\title{
Air quality and environmental sustainability: the situation of Ancona city and its district
}

\author{
G. Latini, M. Pacetti \& G. Passerini \\ Department of Industrial Engineering and Mathematical Sciences, \\ Marche Polytechnic University, Italy
}

\begin{abstract}
The city of Ancona lies on the mid-Adriatic coast and its port has been important even before Rome's millennial history of conquests set off. Today, Ancona still remains a rather important junction for the distribution of goods and the transfer of passengers at European level. The Ancona district also plays host to several industries, mainly located along the Esino Valley. Most of the Ancona Province is a complex valley-coastal area in central Italy comprising valleys, hills, highly populated areas and industrial districts. The two major air pollution sources in the area are a big oil refinery founded in 1950 at Falconara Marittima, and the A14 or "Adriatic Highway", which was completed in the early 1970s leading to an abrupt increase of road traffic. Close to the highly populated city of Falconara Marittima, the A14 intersects another major Highway nearby the local airport and the refinery. This concentration of pollution sources gave Falconara Marittima the unwanted role of guinea pig for what concerned pollution and an increasing demand for information and recovery arose within the population and politicians. Here we present some results of our studies about air pollution due to anthropogenic emissions in such a complex area.
\end{abstract}

Keywords: air pollution, coast-valley environment.

\section{Introduction}

In this paper we review some of the main results of about twenty years of studies about air pollution in the area of Ancona and Esino Valley.

The city of Ancona lies on the mid-Adriatic coast and its port has been important even before Rome's millennial history of conquests set off. Today, Ancona still remains a rather important junction for the distribution of goods and 
the transfer of passengers at European level. This happens due to the simultaneous presence of the port itself a major railroad, a major highway, and a small airport also tailored for the movement of goods. The Ancona district is also dotted by several industries, mainly located along the Esino Valley (about the rightmost third part of Fig. 1). Most of the Ancona Province is a complex valleycoastal area in central Italy comprising valleys, hills, highly populated areas and industrial districts. This area is bounded by the sea to the east, mountains to the west, and by a complex orography to the north and the south. The complex orography results in a considerable variability of local climates within this region and the valleys experience almost continuous mountain and sea breezes driven by the strong difference between the temperatures of the inner valleys, of the coastal areas, and of the Adriatic Sea. The most developed area is the Esino Valley that is characterised by a river bed roughly perpendicular to the coast in a $\mathrm{NE}$ direction. The climate in this area is classified under sub-coastal where there is an all-year-round sea breeze.

Certainly a major source of concern for the environment has always been represented by a major oil refinery founded in 1950 at Falconara Marittima, whose oil pier is visible in Fig.1. The refinery has always represented a kind of "monster" or the source of all the pollution in the surroundings. The situation of refinery became worst due to the increasing necessity of space of both the plant and the city of Falconara. At a certain point their simultaneous growth made the town almost reach refinery fences while a set of tanks nearby the refinery literally surrounded the railroad so that the trains now pass through them.

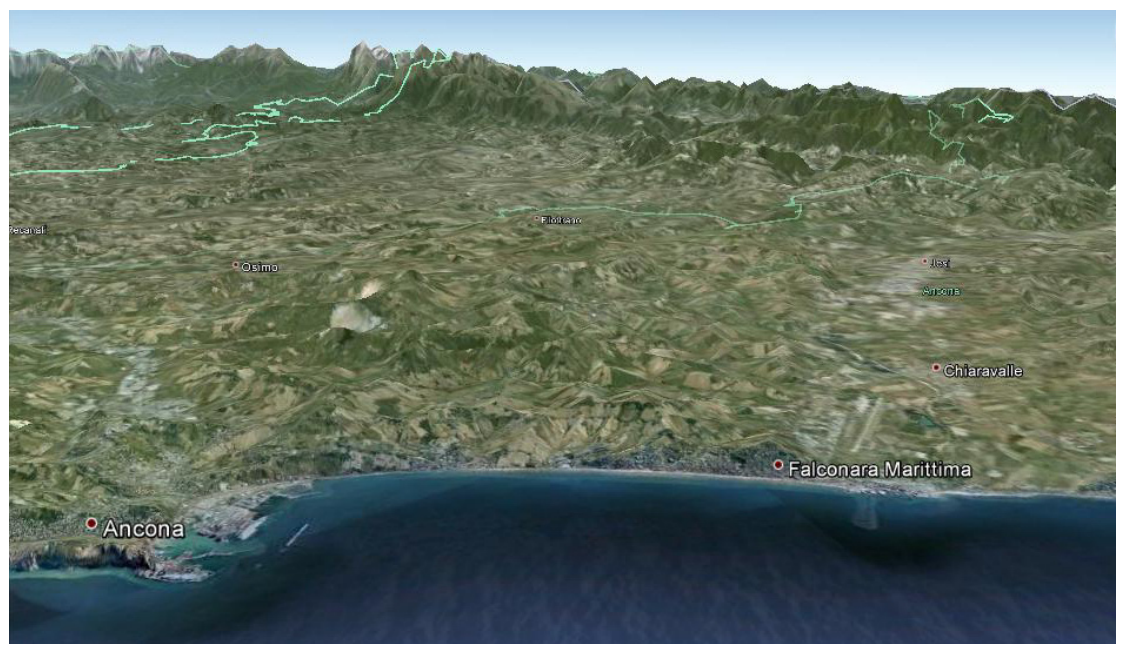

Figure 1: $\quad$ Investigated area.

In the meantime, a major Italian motorway, the A14 or "Adriatic Highway", was completed in the early 1970s leading to an abrupt increase of road traffic. Close to Falconara, the A14 intersects another major highway near the local airport. This concentration of pollution sources gave Falconara Marittima the 
unwanted role of guinea pig for what concerned pollution and an increasing demand for information and recovery arose within the population and politicians.

Also, after several major accidents had occurred in refinery, in 2001 the Environmental Authority of Marche Region declared the area of Ancona, Falconara and lower Esino Valley a Highly-at-Risk of Environmental Crisis Area (Area ad Elevato Rischio di Crisi Ambientale or AERCA). As outlined above, in this area there is a troublesome coexistence of high density settlements, highly hazardous plants, internationally relevant infrastructures. Major environmental problems originated essentially by the interference among industrial activities, transport infrastructure, and residential settlements leading to poor quality of all the environmental matrices (water, air and soil).

More in detail, AERCA hosts five industrial plants at high risk of relevant accident or hazard, the main one being the oil refinery of Falconara that, in the meantime, also started producing electricity through its Integrated Gasification and Combustion Cycle. AERCA covers an area of $85 \mathrm{~km}^{2}$, and it includes a seaside strip ranging from Ancona Harbour in the South to Marina di Montemarciano in the North and, at a right angle, the lower part of the Esino River valley. The coastline is about $30 \mathrm{~km}$ long. On the eve of the new millennium, AERCA was both a major concern for inhabitants and stakeholders and the playground or, better, the training ground for the authors that, upon the wave of fear and discontent were asked to analyse in more depth and detail what was happening. Here we present some major achievements about emission evaluation, secondary pollution assessment and epidemiology.

\section{Pollution sources: Gulliver vs. Lilliputians}

In 2002 we were asked to analyze the emissions and, possibly, the related dispersions of airborne pollutants in the AERCA. At that time we had already analyzed some of the sources and we were aware that the situation was trickier than expected. In particular, we had already applied the Photochemical Box Model (PBM) in the low Esino Valley [1-3] and Aermod Gaussian Plume model to Refinery stacks [4-6] and we had noticed that the refinery, at a first glance, was not to blame as the major source of air pollution in the area. PBM results showed a trend of photochemical smog, typical of a major city rather than that of an industrial area while Aermod modeling led to pollutant concentrations, due to the refinery, far lower than the actual ones. Finally, the network of ten monitoring stations located within AERCA showed several inconsistencies $[7,8]$.

At the time we were asked to produce a kind of emission inventory, the oil refinery was processing nearly 3.9 million tons of crude oil per year. While all the crude oil came by sea tankers, only $30 \%$ of products was shipped and the remaining $70 \%$ was dispatched by tank trucks or tanker lorries. In the meantime, the refinery had also started producing electricity with a potential of 2,000 $\mathrm{GWh}$ per year. While refinery, also due to a major accident, symbolized the main single polluter of the area, thousands small polluters grew constantly in number. In fact, due to the booming economy of Marche and the increasing movement of 
goods, road traffic was peaking: on the A14 only, more than 45,000 average passages a day were monitored, about one third being heavy trucks. Last but not least, local road traffic, mainly directed to Ancona port and Ancona Offices and University, consisted of several thousand cars per hour.

Table 1: Percentage contribution of anthropogenic sources to overall pollutant emissions, in summer and winter.

\begin{tabular}{|c|c|c|c|c|}
\hline \multicolumn{5}{|c|}{ SUMMER } \\
\hline \multirow{3}{*}{ CO (\%) } & Road Traffic & API Oil Refinery & Other sources \\
\cline { 3 - 5 } NOx (\%) & $70-90$ & $<5$ & $10-20$ \\
\cline { 3 - 5 } COV (\%) & $55-60$ & $20-25$ & $10-15$ \\
\cline { 3 - 5 } PTS (\%) & & $50-60$ & $10-15$ & $20-25$ \\
\cline { 3 - 5 } & $40-50$ & $25-35$ & $20-25$ \\
\hline \multicolumn{5}{|c|}{ WINTER } \\
\hline CO (\%) & 10 & $60-70$ & $<5$ & $10-20$ \\
\hline NOx (\%) & $15-20$ & $35-45$ & $15-20$ & $10-15$ \\
\hline COV (\%) & $8-10$ & $40-50$ & $8-12$ & $20-25$ \\
\hline PTS (\%) & $8-10$ & $35-45$ & $20-30$ & $20-25$ \\
\hline
\end{tabular}

The results of our preliminary investigation are summarized in Table.1. As very few (e.g. the authors) expected, the refinery represented only the second or third most important source of airborne pollutants. Namely, the main source of Nitrogen Oxides (NOx) was represented by road traffic that accounted for more than 10 metric tons per day or about the $60 \%$ of total emissions. Volatile Organic Compounds (VOC) emissions were quantified in more than 4 metric tons per day that could be roughly imputed to road traffic, oil refinery, and other industrial activities. However, diffuse emissions of VOC from refinery facilities and tanks were neither computed nor directly measured. Nevertheless, measurements at nearby monitoring stations show such high concentrations of VOC that suggested a significant incidence of such emissions.

The results of our studies suddenly moved part of the attention from the refinery to other sources. While the refinery remained the chief source of concern for a possible relevant accident and/or a release of toxics, all the road traffic became the main offender against the population and the stakeholders so that the entire population of Lilliput started becoming guilty side by side with the Giant Refinery [9].

\section{Secondary pollutants and the quest for precursors}

On August 2000 several Ozone episodes occurred in Falconara Marittima. Data acquired at monitoring stations showed high levels of Ozone and very high levels of Non-Methane Hydrocarbons (NMHC). Ozone concentrations, recorded at two monitoring stations both placed nearby the refinery plant, showed systematic exceeding of alert levels and a marked non-homogeneity both for NMHC and for Ozone horizontal distribution. Concentrations of Nitrogen Oxides (NOx) showed very dissimilar trends being homogenous overland 
(Fig. 2). We found that differential rates of Ozone formation, observed at a distance of few hundred meters, were probably due to $[\mathrm{NMHC}] /[\mathrm{NOx}]$ ratios falling in two different limiting conditions due to emission distributions of precursors, atmospheric circulation, and turbulent mixing. Whenever $[\mathrm{NMHC}]>>[\mathrm{Nox}]$, i.e. in NOx limiting conditions, Ozone production rate was enhanced while, in NMHC limiting conditions (i.e. when $[\mathrm{NMHC}]<<[\mathrm{Nox}]$ ) Ozone formation was delayed by the removal of radicals. The preliminary analysis suggested that the processes that generate Ozone in Falconara could be more efficient than in other urban areas, probably, due to different boundary conditions (local meteorology, local emissions and urban settlements). Therefore, the Ozone production might differ more significantly over short spatial scales than in other urban areas. The study also led to the hypothesis that very reactive, non-routine VOC emissions from point source industries might have been responsible for high Ozone concentrations that were recorded by monitoring stations, resulting in transient high ozone events $[11,12]$.

For a more detailed analysis, to model local scale meteorology the RAMS model (Regional Atmospheric Modeling System,) was applied upon data from Provincial monitoring network and from European Centre for Medium-range Weather Forecast elaborations [12-14]. Simulations showed a persistent and well-formed breeze system performing a complete rotation over the day. A complete rotation of 360 had been found out in a lapse of 24 hours in all critical days. In such scenario, we found strong evidence that Ozone Chemistries in the two neighbouring areas were, during pollution episodes, very different. The very high concentrations of NMHC, recorded at one station might had resulted in a $[\mathrm{NMHC}] /[\mathrm{NOx}]$ ratio that characterized the area as a NOx-limited zone.

At the same time, the nearby district could be characterised as having a low $[\mathrm{NMHC}] /[\mathrm{NOx}]$ ratio. This was confirmed by an accurate analysis of Nitrogen dioxide and Ozone hourly values: an inverse correlation between Nitrogen dioxide and Ozone is visible. Moreover, an increase in the level of Nitrogen dioxide could be noticed while, at the same time, there was a reduction in Ozone levels that is typical of a VOC limited area. In addition, the role of meteorology was significant: the simulations confirm that sea/land breezes played a significant role in the distribution of ozone and transport of Ozone from the coast to the sea and valley areas. The land breeze could transport the photochemical smog and its precursors over the sea. The smog gathered upon the sea and could return to the land during daytime with the sea breeze.

On the basis of our studies, we could conclude that the presence of significant VOC point sources could have influenced the local Ozone chemistry even producing an apparently meaningless behaviour of Ozone concentrations recorded at different nearby monitoring stations. In these circumstances a very accurate monitoring of $\mathrm{NMHC}$, including their speciation was strongly encouraged to assess the real development of phenomena. We also found that special caution should have been used to treat the related pollution episodes. In such cases, the "elective therapy" of limiting the road circulation and/or the industrial activities could trigger a reduction of NOx emissions only, which might result in an increase of Ozone levels and/or in persistence phenomena. 
508 The Sustainable City VII, Vol. 1
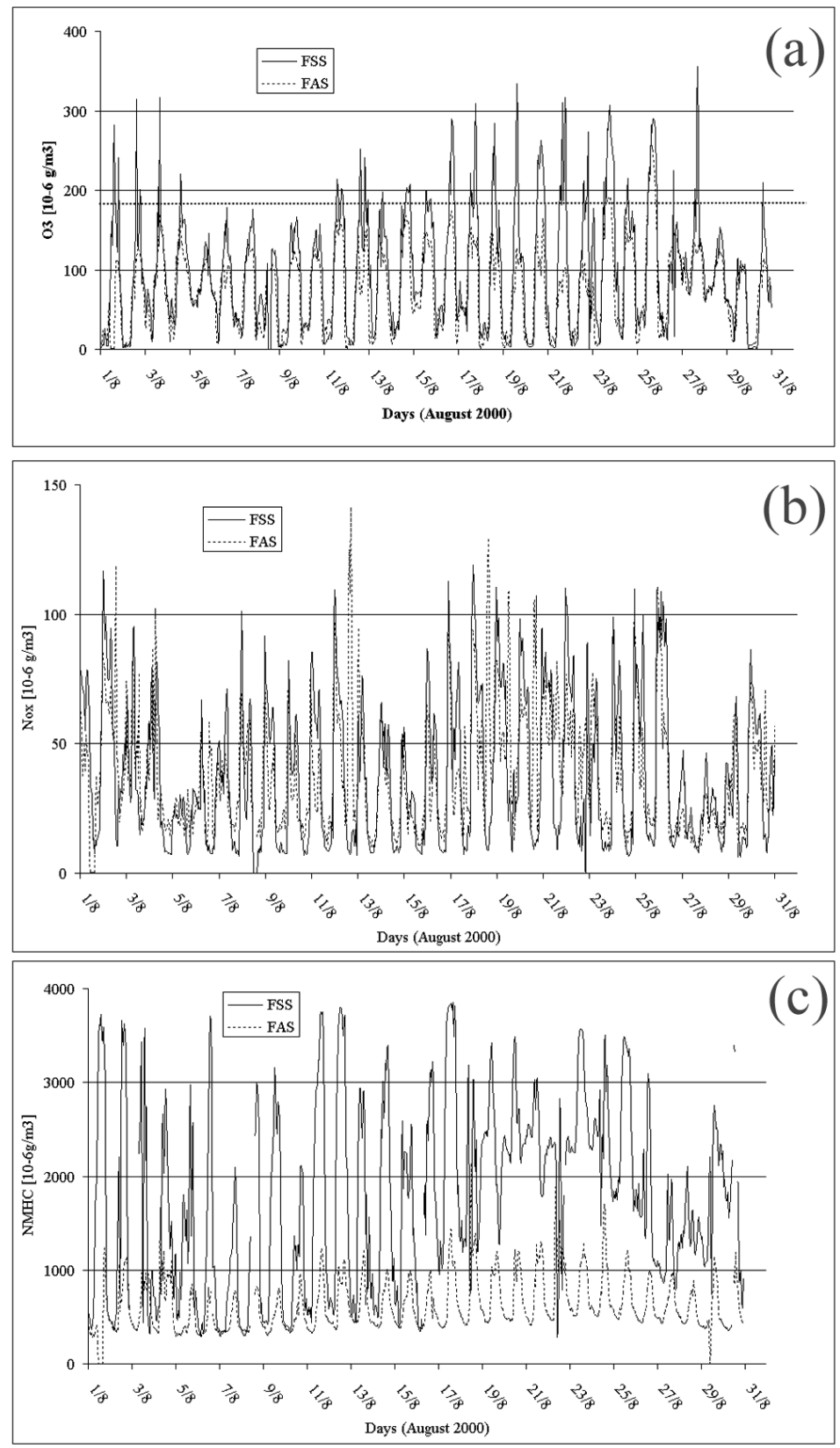

Figure 2: $\quad$ Ozone (a), NOx (b) and NMHC (c) concentrations at monitoring stations during August 2000; the dotted line is the alert level defined by Italian law. 


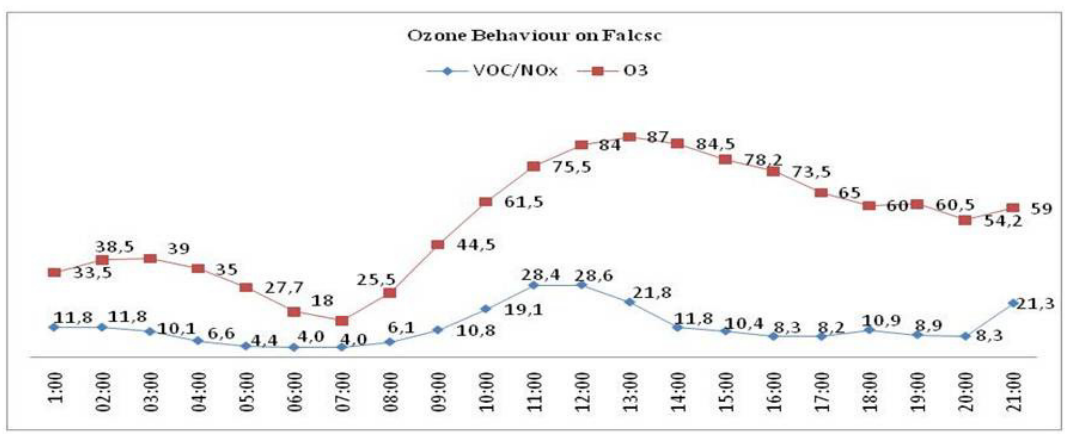

Falcsc Day Cycle

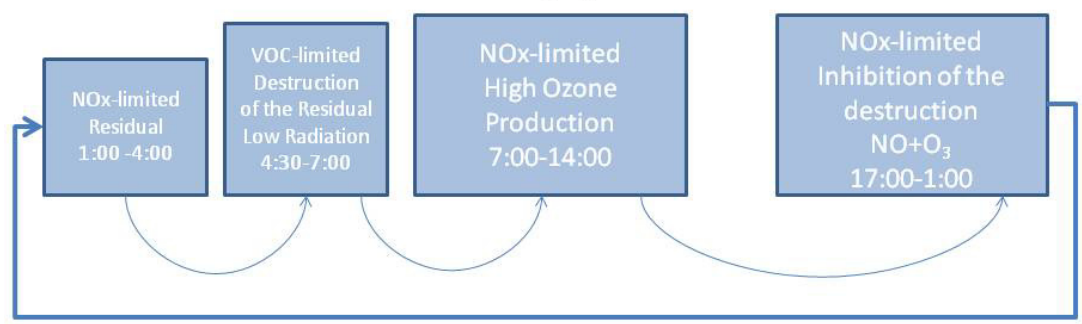

Figure 3: Ozone day cycles at "Falconara Scuola".

During the episodes of 2000, the authorities limited refinery activities and road traffic. This resulted in an abrupt local decrease of NOx emissions, especially during the day. At the same time, VOC emissions mainly due to diffuse release from refinery pipes and tanks remained substantially stable. This possibly led to an unwanted result: a momentary further increase of Photochemical Smog. After the results of our studies a special attention was focused on both the reduction of diffuse VOC emissions from refinery and NOx overall reduction from all sources. While NMHC concentrations monitored at Falconara stations show a possible reduction of VOC emissions, NOx values suggest that emissions are still at very high levels, mainly due to road traffic.

To better understand the Ozone behaviour in lower Esino Valley, a new set of experiments is undergoing by means of a tool called OSAT (Ozone Source Apportionment Technology) [15] implemented within the photochemical model CAMx (Comprehensive Air quality Model with eXtensions) [16]. By means of OSAT [17] it was possible to discriminate between NOx-limited and VOClimited condition formation (Fig. 3). Information about the contribution of the different types of source emission-groups, allowed us to develop a tentative best Ozone-control strategy to lower Ozone peaks and to avoid ozone episodes. The study includes comparison between several concentration data sets related to different species (e.g. $\mathrm{NO}, \mathrm{NO}_{2}, \mathrm{VOC}, \mathrm{O}_{3}$ ) given as results by the photochemical model (under certain meteorological, orography and emission data) and the concentrations recorded at monitoring stations at various locations. It was also possible to analyze the ozone behaviour in diverse areas based on land use 
(e.g. Road, Country, Industrial Area, etc.). Finally, new simulation scenarios, with a reduction of chemicals in specific emission groups, were launched to analyze the ozone response.

\section{A new issue: PM and its speciation}

We know that there is a direct link between exposure to fine and ultra-fine Particulate Matter (respectively PM10 and PM2.5) and several pathologies of vascular system. The evaluation of long-term exposure to airborne pollutants is usually carried out through statistical models tuned by means of concentration data measured at monitoring stations. By knowing the amount of PM inhaled by a number of inhabitants during a certain time span or, at least, their rate of exposure, we can statistically link strokes, heart attacks, and other vascular pathologies to such morbidity sources. To achieve such statistical information, an adequate time span should be investigated. In general, an analysis performed over ten years of exposure is considered enough to achieve a good comprehension of possible links between long-term exposure to one or more airborne pollutants and certain pathologies or certain groups of pathologies.

Whenever concentration data are not available, linking human mortality and/or human morbidity to the exposure to airborne pollutants is virtually impossible. Obviously, linking pathologies to pollution sources results impossible as well. This condition is especially frustrating both for physicians and for policy makers. The physicians do not know part of the game since they lack crucial information on the development of diseases. Policy makers cannot perform any kind of prevention and they are not allowed to enforce specific measures to avoid further damages to humans and biosphere.

From this point of view, the long-term exposure to PM10 and PM2.5 represents a very special and unfortunate study field, especially in Italy. In fact, most monitoring stations in Italy have started recording PM10 data only few years ago while, to day, very few trace PM2.5. This makes impossible to perform a truly effective statistical analysis to link diseases with pollution. Moreover, exposure to an amount of PM can result in very different effects to human health depending upon the speciation of the particulate. A long-term leave at seaside will result in a long-term exposure to a huge amount of PM10 but most of it is simply what a vacationer pays for: marine air or, better, marine aerosol: nobody has been yet allowed to claim damages for having been forced to breathe marine aerosol. However, let us imagine that a big company runs a potentially polluting business, e.g. a refinery, very close to the seashore. This might contribute to the airborne concentration of PM by few percentages but such contribution could be very dangerous, depending on the kind of particulate released and added to environment. For instance, a comparatively small amount of certain heavy metals may result in an abrupt increase of morbidity.

To make the scenarios even trickier, we know that most of the particulate we breathe is what we call secondary particulate i.e. particulate that forms by chemical reactions, through chemical combination of precursors. Precursors are chemicals usually present into the atmosphere due to anthropogenic activities. 
They may react either by means of energy sources (e.g. solar radiation as seen in previous chapter) or in presence of aerosols, catalysts etc. or simply by chemical association, to form secondary particulates. Nitrogen-based secondary particulate is both a rather important fraction of the airborne PM (namely of PM2.5) and a potential key player in the development of vascular diseases.

In 2006, Local Authorities started to monitor vascular diseases within AERCA trying to assess the correlation between long-term exposure to PM and the related emission sources. Due to the lack of data, they asked us how to deal with the problem and we suggested performing a complete dispersion analysis over the entire area and upon several years of time spam. Thus, we suggested applying a well-know state-of-the-art regulatory model such as Aermod [4, 5]. After a preliminary study, to provide physicians with proper data, we have applied the Aermod model to simulate the concentrations of PM10 during ten years from 1997 to 2006 . Through several simulations, we let researchers to analyze the contributions from different kinds of sources. We must point out and we must stress that this methodology is rather heterodox. Between all, we had to modify and re-compile the model kernel in order to deal with a very high number of emission sources that resulted in several thousands of point sources. As a result, performing one year of analysis required about two weeks on a quad-core PC while the results of calculi were stored on 5GB text files that required developing a proper parser to deal with it [18].

Table 2: $\quad$ Number of exceedances of limit value in selected receptors.

\begin{tabular}{|c|c|c|c|c|c|c|c|c|c|c|c|}
\hline coord-X & coord-Y & 1997 & 1998 & 1999 & 2000 & 2001 & 2002 & 2003 & 2004 & 2005 & 2006 \\
\hline 366181,00 & 4834014,50 & 23 & 26 & 12 & 13 & 10 & 3 & 3 & 1 & 1 & 3 \\
\hline 366117,94 & 4834251,50 & 22 & 26 & 10 & 13 & 10 & 1 & 5 & 2 & 3 & 2 \\
\hline 365983,25 & 4834132,00 & 23 & 26 & 14 & 11 & 10 & 0 & 2 & 0 & 0 & 2 \\
\hline 366112,81 & 4833954,00 & 30 & 29 & 17 & 16 & 11 & 3 & 5 & 2 & 4 & 4 \\
\hline 366362,22 & 4834040,00 & 15 & 17 & 7 & 9 & 7 & 0 & 3 & 0 & 0 & 2 \\
\hline 366280,56 & 4833950,50 & 36 & 40 & 20 & 24 & 19 & 0 & 6 & 0 & 2 & 4 \\
\hline 365828,12 & 4834120,50 & 41 & 40 & 32 & 24 & 18 & 3 & 3 & 2 & 2 & 0 \\
\hline 366464,97 & 4834459,00 & 48 & 59 & 38 & 43 & 20 & 2 & 8 & 4 & 2 & 4 \\
\hline 364678,16 & 4835625,00 & 51 & 54 & 43 & 44 & 20 & 6 & 9 & 6 & 3 & 6 \\
\hline 365654,62 & 4834238,50 & 72 & 89 & 60 & 76 & 43 & 4 & 3 & 4 & 3 & 8 \\
\hline 366357,41 & 4834243,50 & 17 & 24 & 9 & 11 & 8 & 0 & 2 & 0 & 1 & 2 \\
\hline 365095,00 & 4834591,00 & 119 & 144 & 115 & 128 & 62 & 10 & 14 & 5 & 6 & 11 \\
\hline 366557,53 & 4834447,00 & 36 & 41 & 26 & 25 & 14 & 2 & 6 & 4 & 2 & 5 \\
\hline 364444,62 & 4834499,00 & 11 & 15 & 7 & 14 & 2 & 0 & 0 & 0 & 0 & 0 \\
\hline 365025,12 & 4828382,50 & 8 & 9 & 3 & 6 & 3 & 0 & 0 & 0 & 0 & 0 \\
\hline 364974,75 & 4829157,00 & 32 & 36 & 20 & 24 & 8 & 0 & 0 & 0 & 0 & 0 \\
\hline 364974,75 & 4829157,00 & 32 & 36 & 20 & 24 & 8 & 0 & 0 & 0 & 0 & 0 \\
\hline
\end{tabular}

Some summarised results are shown in Fig. 4 and Table 2. In the figure, we resume, by means of circles, the number of times the concentration of PM10 exceeded the present limit of $50 \mu \mathrm{g} / \mathrm{m}^{3}$. The bigger the circles are, the bigger the number of exceedances in the period is. The table shows the number of exceedances in selected receptors year by year. By analyzing the figure and the table, we can already assert several hypotheses. The position of the most polluted receptors is not close to major stacks. This confirms a well-known fact: stacks disperse pollutant over a quite large area. Unfortunately, our simulations do not 
take into account secondary pollution also due to diffuse emissions such as evaporative emissions that may account for several times stack emissions. The position of most polluted receptors is close to major highways. Again, it is well known that emissions due to road traffic tend to remain nearby since exhaust pipes emit at ground level and at rather low temperatures. This makes living close to main roads very dangerous. In addition, in this case, an amount of particulate matter is not taken into account, due to tire consumption, brake friction, and re-lifting.

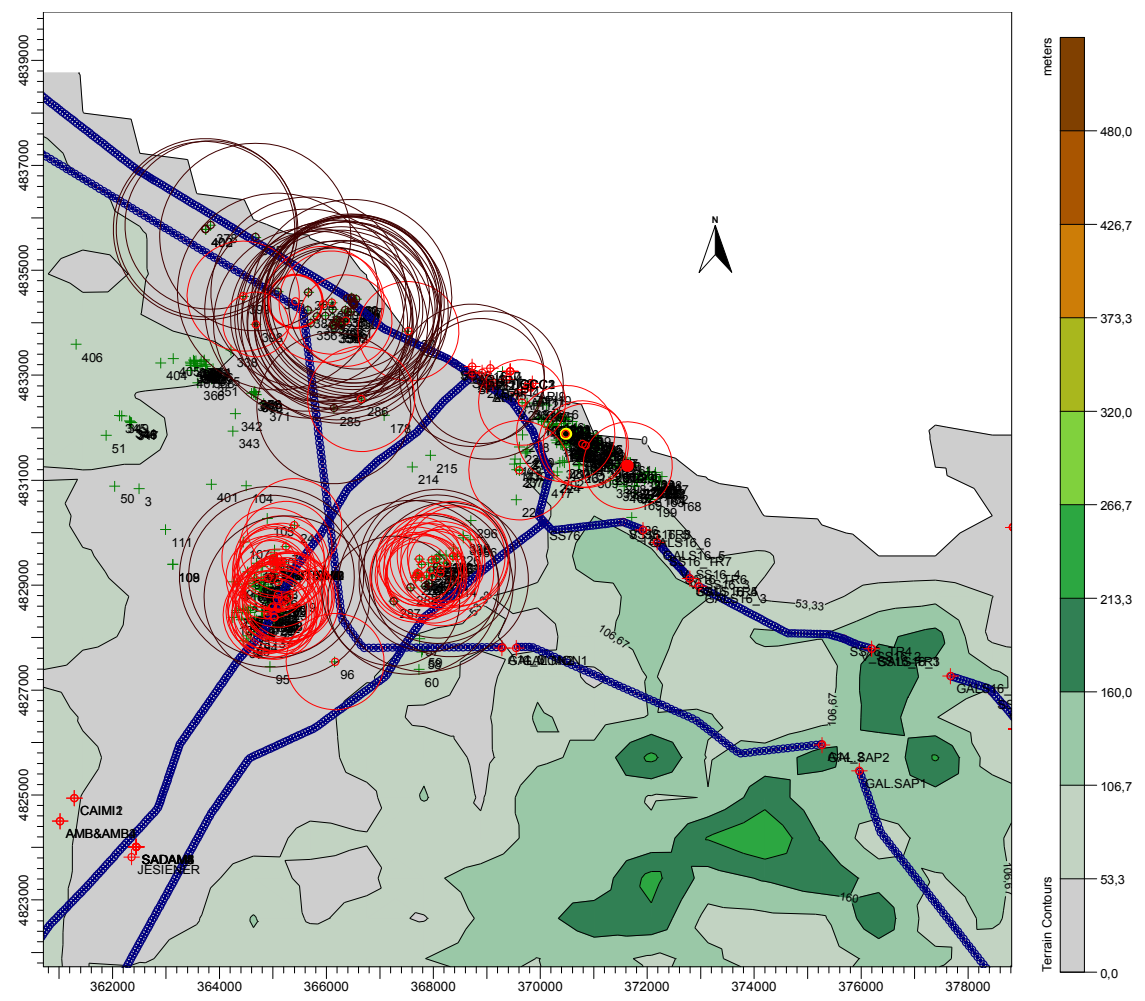

Figure 4: Graphical representation in AERMOD. The most exposed receptors are represented in green. In black, the receptors with exceedances of limit value lasted until 2006. In red, the receptors with a frequency of exceedances that tend to zero after 2001.

A general decrease of air pollution took place in the last years mainly due to the adoption of Best Available Techniques in industrial processes and emission abatements and, above all, due to the adoption of the so-called "Euro" standards for new cars, coaches, and trucks. By analyzing the position of receptors and the time span of exceedances, we can easily understand that the reduction of emissions due to the adoption of Euro standards was preeminent in the area. In fact, red circles nearby major highways crossings and exits show the related 
strong decrease in local particulate concentrations. On the other hand, black and green circles show that the worst situation depends from the "blend" of PM due to the presence of both smoke plume from stacks and local emissions from cars and heating systems. We must stress, again, that all such conditions are evaluated by dispersion analysis. Such exceedances are postulated by Aermod taking into account only a part of the emissions and do not taking into account secondary pollution, non-anthropogenic sources and some anthropogenic sources.

\section{Conclusions}

A complex coastal environment, which is densely populated, which hosts several industries, a network of infrastructures and a major port, cannot be fully explained within the scope of one paper. However this paper was intended to show that in such a complex situation, state-of-the art modelling is required and effective. This primarily means that models must be up-to-date but also means that input data should be almost exhaustive. Using default input values for most of variables in new models is very frustrating since we know that such models require a accurate and precise knowledge of all parameters.

Between all the requirements in terms of input data, the lack of speciation data, both for precursors (NOx and VOC) and for some primary and secondary pollutants (PM and SOx) represents the main urge. If we do not input speciation data, models use a predetermined set of them. Unfortunately it is almost impossible to match the proper ones due to the extreme variability of factors but also due to the different environments. In fact, models are usually developed and tuned in USA and all the related default data are usually evaluated in "USA Scenarios". In conclusion we think that a proper local speciation at least of reactive hydrocarbons and fine PM has to be performed routinely in any densely populated area also to let scientist to model properly air pollution.

\section{Acknowledgement}

This work has been supported by Fondazione Cariverona of Italy.

\section{References}

[1] G. Latini, R. Cocci Grifoni, G. Fava, G. Passerini, Applicability of a Photochemical Box Model over Complex Coastal Areas, in Air Pollution VII, WIT Press, Southampton (GB), pp. 623-632, 1999.

[2] G. Latini, R. Cocci Grifoni, G. Passerini, T. Tirabassi, Evaluation of mixing Height over Complex Coastal Terrain, in Air Pollution VII, WIT Press, Southampton (GB), pp. 697-706, 1999.

[3] G. Latini, R. Cocci Grifoni, G. Passerini, S. Tascini, A simplified approach to photochemical box model meteorological data input, in Environmental Coastal Regions III, WIT Press, Southampton (GB), pp. 363-372, 2000. 
[4] G. Latini, R. Cocci Grifoni, G Passerini, Application of new generation models over complex coastal areas, in Coastal Environment IV, WIT Press, Southampton (GB), pp. 385-394, 2002.

[5] G. Latini, R. Cocci Grifoni, G. Passerini, The Optimal Choice of AERMOD Input Data in Complex Areas., in Air Pollution Modeling and its Applications, Kluwer Academics Plenum pp. 513-514, 2002.

[6] G. Latini, R. Cocci Grifoni, G Passerini, S. Tascini, Applications of Rams and Aermod models to evaluate pollution dispersion in a coastal valley, in Air Pollution Modelling and its Applications, Kluwer Academic/Plenum, pp. 627-631, 2004.

[7] R. Cocci Grifoni, L. Magnaterra, G Passerini, S. Tascini, Analysis of environmental time series in the frequency domain, in Air Pollution XI, WIT Press, Southampton (GB), pp. 203-212, 2003.

[8] G. Latini, G. Passerini, Quality assessment of monitored environmental data in the frequency domain, Proceedings of 2009 IEEE Workshop on Environmental, Energy, and Structural Monitoring Systems.

[9] G. Latini, R. Cocci Grifoni, G Passerini Sustainability of transportation systems: air pollution scenarios in Sustainable Planning and Development, WIT Press, Southampton (GB), pp. 213-222, 2003.

[10] G. Latini, R. Cocci Grifoni, G. Passerini, S. Tascini, A neuro-fuzzy model for ozone forecasting, in Air Pollution XIII, WIT Press, Southampton (GB), 2005.

[11] G. Latini, R. Cocci Grifoni, G. Passerini and S. Tascini, A preliminary evaluation of unexpected ozone levels measured in Falconara, Italy, in Coastal Environment VI, WIT Press, Southampton (GB), pp. 409-518, 2006.

[12] G. Latini, R. Cocci Grifoni, G. Passerini and S. Tascini, The importance of meteorology in determining surface Ozone concentrations - A neural network approach, in Coastal Environment IV, WIT Press, Southampton (GB), pp. 405-414, 2002.

[13] R. Cocci Grifoni, L. Magnaterra, G Passerini, S. Tascini, Importance of local meteorology in coastal ozone dynamics: a case study, in Air Pollution XI, WIT Press, Southampton (GB), pp. 95-104, 2003.

[14] R. Cocci Grifoni, G Passerini, S. Tascini, An assessment of the sea/valley breeze and its impact on ozone behaviour, in Coastal Environment V, WIT Press, Southampton (GB), pp. 257-267, 2004.

[15] S. Arunachalam and K. Baker, Peer Review of Source Apportionment Tools in CAMx and CMAQ, EP-D-07-102 U.S. EPA, OAQPS C439, 2009.

[16] Website www.camx.com

[17] G. Passerini, S. Carletti, G. Ciarelli, Evaluation of ozone Behavior in a Complex Coastal Environment, Proceedings of $8^{\text {th }}$ Conference on Environmental Engineering, Vilnius, Lithuania, May 2011.

[18] G. Latini, G. Passerini, F. Principi, Evaluation of long-term exposure to pollutants by means of a dispersion model, Proceedings of 2009 IEEE Workshop on Environmental, Energy, and Structural Monitoring Systems. 